\title{
Cross-Linked ZnO Nanowalls Immobilized onto Bamboo Surface and Their Use as Recyclable Photocatalysts
}

\author{
Chunde Jin, Jingpeng Li, Jin Wang, Shenjie Han, Zhe Wang, and Qingfeng Sun \\ School of Engineering, Zhejiang Agricultural and Forestry University, Lin'an 311300, China \\ Correspondence should be addressed to Qingfeng Sun; qfsun@nefu.edu.cn
}

Received 14 May 2014; Accepted 22 June 2014; Published 10 July 2014

Academic Editor: Chuanfei Guo

Copyright ( 92014 Chunde Jin et al. This is an open access article distributed under the Creative Commons Attribution License, which permits unrestricted use, distribution, and reproduction in any medium, provided the original work is properly cited.

\begin{abstract}
A novel recyclable photocatalyst was fabricated by hydrothermal method to immobilize the cross-linked $\mathrm{ZnO}$ nanowalls on the bamboo surface. The resultant samples were characterized by using scanning electron microscopy (SEM), X-ray diffraction (XRD), energy dispersive spectroscopy (EDS), and Fourier transformation infrared (FTIR) techniques. FTIR spectra demonstrated that the cross-linked wurtzite $\mathrm{ZnO}$ nanowalls and bamboo surface were interconnected with each other by hydrogen bonds. Meanwhile, the cross-linked ZnO nanowalls modified bamboo (CZNB) presented a superior photocatalytic ability and could be recycled at least 3 times with a photocatalytic efficiency up to $70 \%$. The current research provides a new opportunity for the development of a portable and recycled biomass-based photocatalysts which can be an efficiently degraded pollutant solution and reused several times.
\end{abstract}

\section{Introduction}

In recent years, environmental problems such as air and water pollution had provided the impetus for sustained fundamental and applied research in the area of environmental remediation [1-3]. The wastewater from textile, paper, plastics, rubber, cosmetics, and other drying industries contains residual dyes, which are not readily biodegradable [4]. These dyes were invariably left in the industrial waste and consequently discharged mostly to surface water resources, which were greatly harmful to the environment, hazardous to human health, and difficult to degrade by traditional techniques [5]. Recently, nanosized semiconductor materials like $\mathrm{TiO}_{2}[6,7]$, $\mathrm{ZnO}[8,9]$, and $\mathrm{SnO}_{2}[10]$, which mediate photocatalytic decomposition of organic molecules, are paid tremendous attention for the treatment of the organic pollutants of wastewater $[11,12]$. One of the most important semiconductor photocatalysts, especially for $\mathrm{ZnO}$, has been greatly focused on the photodegradation of the environmental pollutants due to its high catalytic activity, low cost, and environmental friendliness [13]. In the previous research, the structure or morphology of the photocatalysts is considered to have a strong relationship with their photocatalytic performance. For instance, Guo et al. $[14,15]$ have demonstrated that morphology of materials can be well controlled in some important photocatalytic materials like $\mathrm{BiOCl}$ and $\mathrm{Bi}_{2} \mathrm{~S}_{3}$. Also, the interconnected nanostructures can greatly improve their mechanical strength [16]. Many organic pollutants, such as rhodamine $\mathrm{B}$, methyl orange, phenols, dye, and carboxylic acids, can be photodegraded by nanosized $\mathrm{ZnO}$ materials under UV or visible light irradiation [8, 17-19]. The development of an efficient, green, and low-cost method for the removal of organic pollutant compounds is essential for the protection of the environment [20]. Wood, bamboo, and cellulose are usually considered good candidates as host materials of nanomaterials because they can improve the stability, retain the special morphology, and control the growth of nanoparticles. Meanwhile, these cellulose-based materials have always been environmentally friendly, easily biocompatible, easily designed, and feasibly biodegraded $[21,22]$. Therefore, the inorganic nanomaterials/polymer composite materials can be considered as a portable catalyst.

Our previous research has confirmed that hydrothermal method is a facile method for the growth of inorganic nanomaterials on the surface of cellulose-based materials such as wood [23-27]. Moreover, the porous wood substrate rich in abundant hydroxyl groups provides a chance for the deposition of inorganic nanomaterials in the hydrothermal 
process [28]. The porous structure in the surface and hydroxyl groups have been shown to be very useful for the creation of an inorganic nanoparticle/polymer catalyst. Bamboo surface with similar chemical constituents of wood can also provide a suitable template to prepare $\mathrm{ZnO}$ nanomaterial through strong hydrogen bond and electronic interactions under hydrothermal conditions. Herein, in our present work, a portable catalyst of cross-linked $\mathrm{ZnO}$ nanowalls/bamboo composites was prepared for the photocatalytic application under UV light irradiation. Compared with those powder photocatalysts, the as-prepared photocatalyst was very easily separated from the dye aqueous solution and cyclically used. We hope to provide a novel method for easy creation of $\mathrm{ZnO}$ nanomaterial bound with cellulose-based materials. The paper may provide a new and "green" pathway for the design and fabrication of photocatalytic materials to solve the problem of organic pollution.

\section{Experimental}

2.1. Raw Materials. All the chemicals were supplied by Shanghai Boyle Chemical Co., Ltd., and used as received. The moso bamboo was cut into slices with a size of $50 \mathrm{~mm}$ (tangential) $\times 20 \mathrm{~mm}($ radial $) \times 2 \mathrm{~mm}$ (longitudinal). The bamboo slices were ultrasonically rinsed in deionized water and ethanol for $30 \mathrm{~min}$ and vacuum-dried at $60^{\circ} \mathrm{C}$ for $48 \mathrm{~h}$. The original bamboo sample was abbreviated as OB.

2.2. Immobilization of the Cross-Linked $\mathrm{ZnO}$ Nanowalls on the Bamboo Surface. In a typical preparation method, zinc acetate dihydrate $(0.75 \mathrm{M})$ was dissolved in methanol at $60^{\circ} \mathrm{C}$ under vigorous magnetic stirring. Then, the above solution was added dropwise to a solution of monoethanolamine with volume ratio of $1: 1$ at room temperature. The resulting mixture solutions were then stirred at $60^{\circ} \mathrm{C}$ for $30 \mathrm{~min}$. The $\mathrm{ZnO}$ sol solution was thus obtained. Immobilization of the cross-linked $\mathrm{ZnO}$ nanowalls on the bamboo surface was employed by the following process. Firstly, bamboo slices were coated by $\mathrm{ZnO}$ sol through a repeated dip-coating process. The obtained bamboo slices were immersed into the $\mathrm{ZnO}$ sol solution for $5 \mathrm{~min}$. After that, these bamboo slices were dried at $80^{\circ} \mathrm{C}$ for 5 hours using a drying oven. The procedures from dip-coating to drying were repeated 5 times to obtain multilayer films. The bamboo sample coated by $\mathrm{ZnO}$ sol was abbreviated as ZSB. Then, the cross-linked $\mathrm{ZnO}$ nanowalls were grown via an aqueous solution route with a mixture solution consisting of zinc nitrate hexahydrate $(0.05 \mathrm{M})$, hexamethylenetetramine $(0.05 \mathrm{M})$, polyvinyl alcohol $(0.06 \mathrm{M})$, and deionized water $(250 \mathrm{~mL})$. The main growth of the cross-linked $\mathrm{ZnO}$ nanowalls was carried out at $95^{\circ} \mathrm{C}$ for $1 \mathrm{~h}$. The samples were collected and rinsed with distilled water several times. Finally, the samples were dried at $50^{\circ} \mathrm{C}$ for $48 \mathrm{~h}$. The cross-linked $\mathrm{ZnO}$ nanowalls that treated the bamboo were abbreviated as CZNB.

2.3. Characterizations. Surface morphology of samples was characterized by scanning electron microscopy (SEM, FEI, Quanta 200). The chemical compositions of the untreated and treated bamboo were measured by energy dispersive spectroscopy (EDS) in connection with SEM. Crystalline

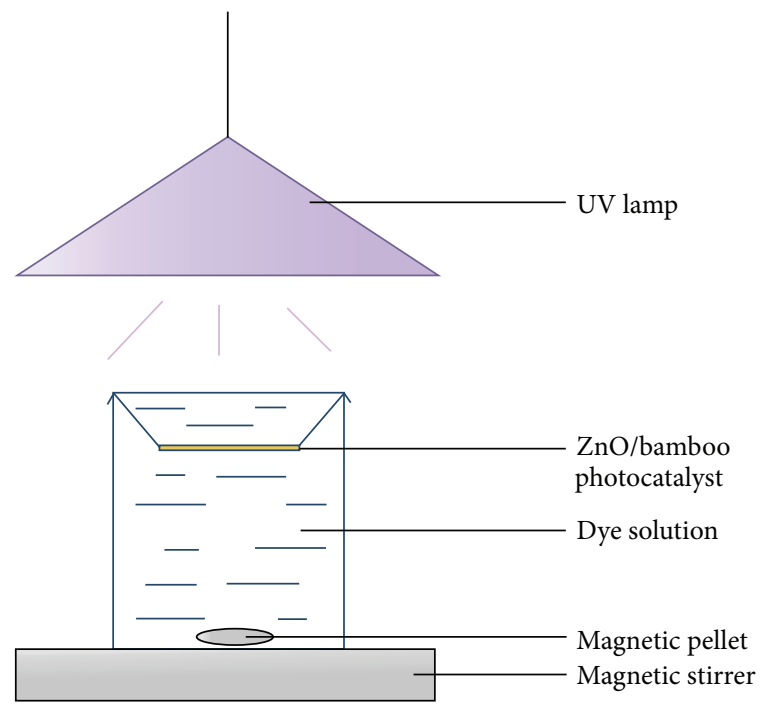

FIGURE 1: Experimental setup of photocatalytic degradation.

structures of the samples were identified by X-ray diffraction technique (XRD, Rigaku, D/MAX 2200) operating with $\mathrm{Cu} \mathrm{K} \alpha$ radiation $(\lambda=1.5418 \AA)$ at a scan rate $(2 \theta)$ of $4^{\circ} \mathrm{min}^{-1}$, $40 \mathrm{Kv}$, and $40 \mathrm{~mA}$, ranging from $5^{\circ}$ to $80^{\circ}$. Surface chemical compositions of the samples were characterized by Fourier transformation infrared (FTIR) spectroscopy using a Thermo Magna-IR 560 E.S.P FTIR spectrometer (Nicolet).

2.4. Measurement of Photocatalytic Activity. The photocatalytic activities of the as-prepared samples were assessed by monitoring the degradation of rhodamine $\mathrm{B}(\mathrm{Rh} \mathrm{B})$ solutions at ambient temperature. A $35 \mathrm{~W}$ mercury lamp (Hg lamp) (Shanghai Rongbo Co., China) with main wavelength of $254 \mathrm{~nm}$ was used as ultraviolet light source. The degradation experiments were carried out in a $100 \mathrm{~mL}$ beaker, opening to air, and the distance between the lamp and the solution was about $10 \mathrm{~cm}$. Magnetic stirring at a speed of $100 \mathrm{rpm}$ was applied to the solution. For a comparative study of photocatalytic activity, blank experiments using similar conditions without the addition of photocatalysts were performed. The bamboo slices with $\mathrm{ZnO}$ were added to $100 \mathrm{~mL}$ of the $\mathrm{Rh} B$ solution $\left(50 \mathrm{mg} \mathrm{L}^{-1}\right)$ with ultrasonic treatment for $30 \mathrm{~min}$. Before the photocatalytic degradation, the solution was magnetically stirred in dark environment for $60 \mathrm{~min}$ to reach the adsorption equilibrium. The change of solution concentration in every $30 \mathrm{~min}$ was measured to judge the absorbability of catalysts in the dark. At every interval during the process of $3 \mathrm{~h}$, a series of aqueous solutions in a certain volume were collected and were then analyzed on a TU1901 UV-vis spectrophotometer (TU-190, Beijing Purkinje, China), and its maximum absorption wavelength of $\mathrm{Rh} B$ was $554.5 \mathrm{~nm}$.

The efficiency was calculated by the following equation:

$$
Y=100 \times\left(\frac{\left(C-C_{0}\right)}{C_{0}}\right),
$$

where $C_{0}$ and $C$ are the initial dye concentration and the concentration at time $t$, respectively. The schematic diagram of the photocatalytic reactor was shown in Figure 1. 


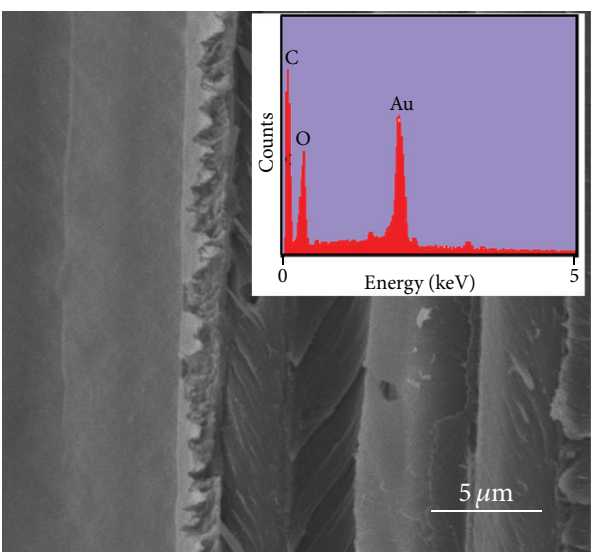

(a)

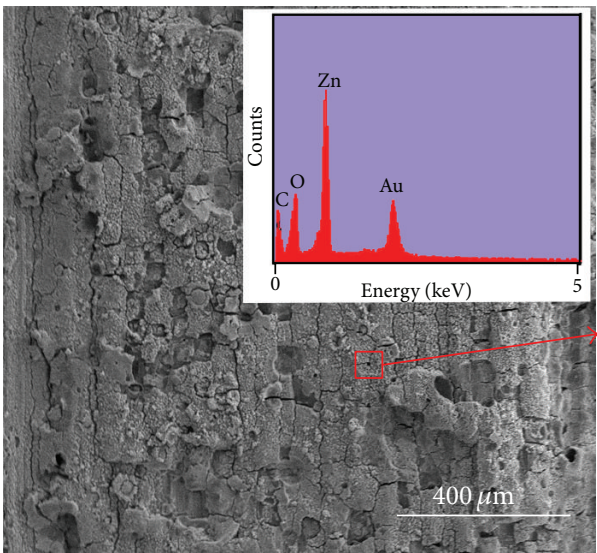

(c)

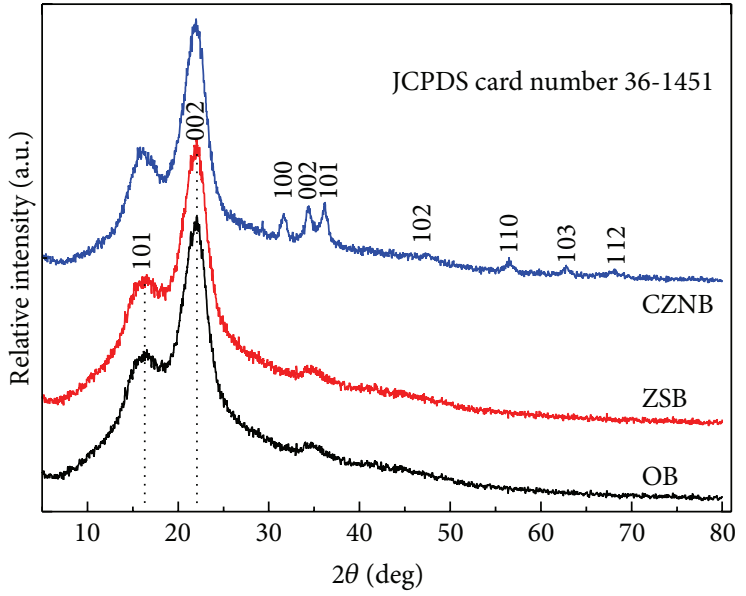

(e)

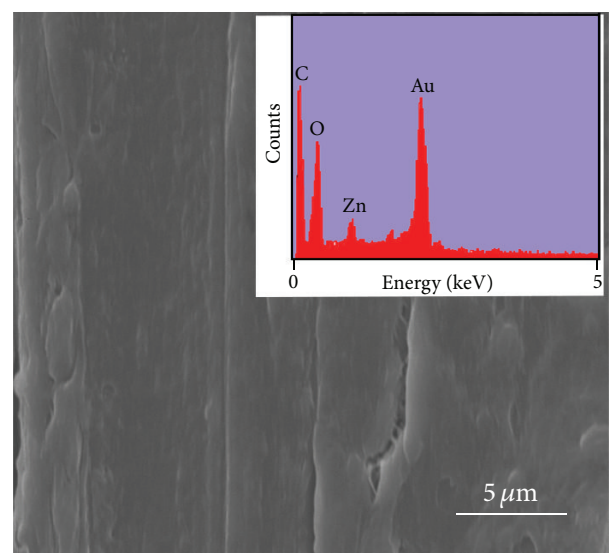

(b)

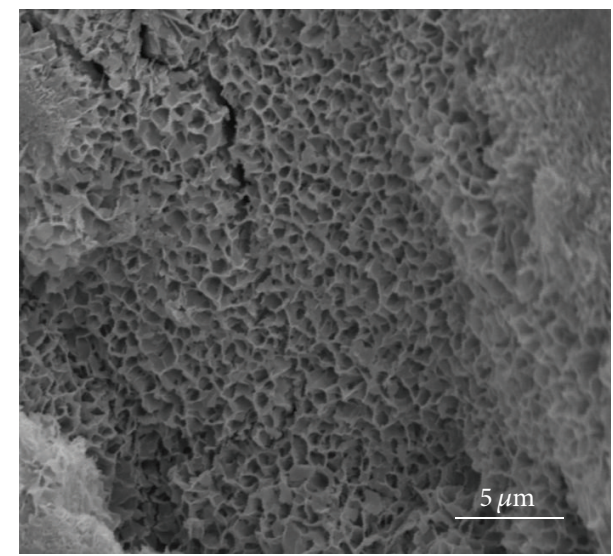

(d)

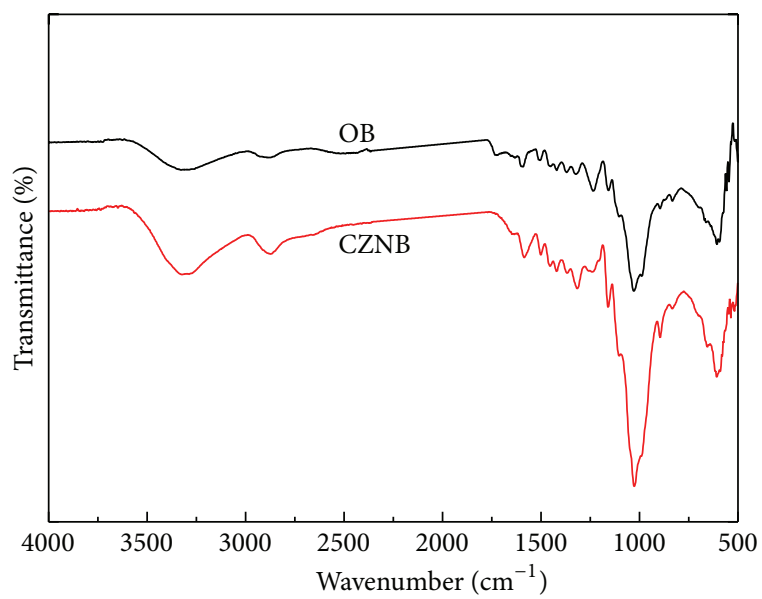

(f)

FIGURE 2: SEM images of the surface of (a) OB. The inset was its corresponding EDS spectrum. (b) ZSB. The inset was its corresponding EDS spectrum. CZNB at (c) low and (d) high magnification, respectively. The inset in (d) was its corresponding EDS spectrum. (e) XRD spectra of OB, ZSB, and CZNB. (e) FTIR spectra of OB and CZNB.

\section{Results and Discussion}

Figure 2(a) showed SEM image of the surface of OB. The microstructures of $\mathrm{OB}$ could be clearly observed, which displayed a kind of nonsmooth morphological surface. The inset in Figure 2(a) gave a typical EDS spectrum of the chemical compositions for $\mathrm{OB}$. Only $\mathrm{C}, \mathrm{Au}$, and $\mathrm{O}$ elements could be detected from the spectrum. The element of $\mathrm{Au}$ came from the coating layer used for SEM observation and $\mathrm{C}$ and $\mathrm{O}$ elements were from the bamboo substrate. After 


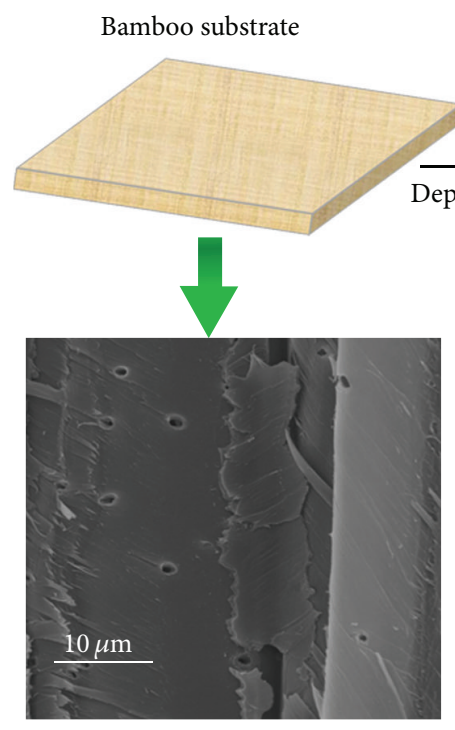

(a)

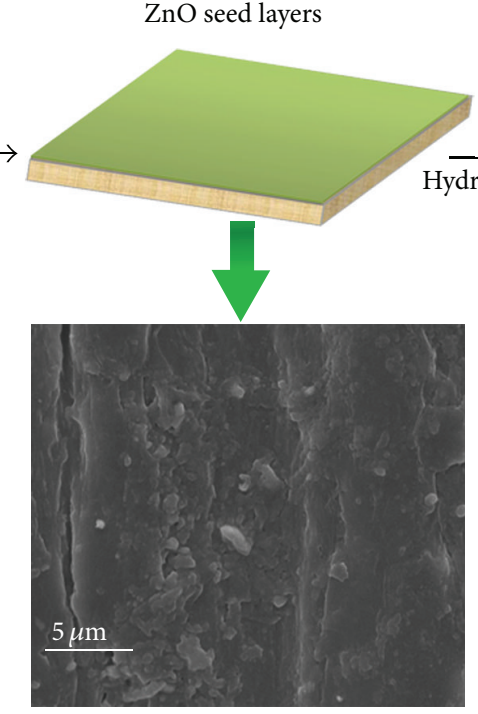

(b)

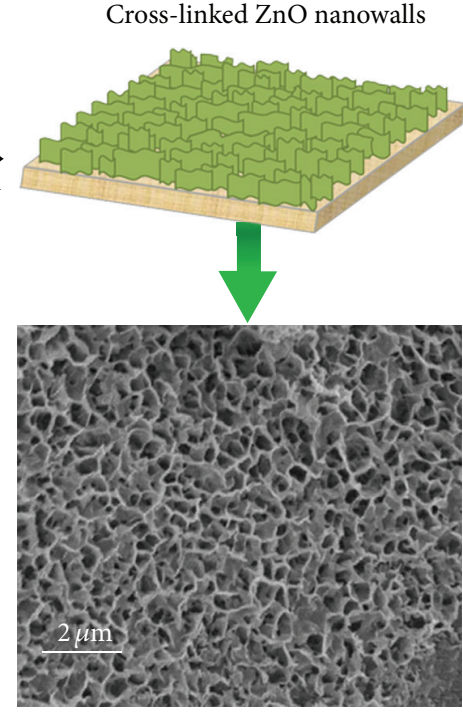

(c)

FIgURE 3: Schematic illustration of the formation process of CZNB.

the dip-coating process by $\mathrm{ZnO}$ sol, the microstructures of $\mathrm{OB}$ were disappeared, which presented a smooth and clean surface as shown in Figure 2(b). From the inset of this figure, besides the signal of carbon and oxygen elements, weak peaks corresponding to zinc element were also observed in the spectrum of $\mathrm{ZnO}$ sol coated bamboo substrate, indicating the formation of $\mathrm{ZnO}$ sol on the bamboo surface. Figure 2(c) showed a SEM image of CZNB at low magnification. From the SEM image, it could be clearly seen that thickly $\mathrm{ZnO}$ nanostructured materials had been immobilized onto the bamboo surface after the hydrothermal reaction. In the magnified SEM image (Figure 2(d)), the morphology of CZNB could be clearly observed. These cross-linked $\mathrm{ZnO}$ nanowalls were randomly oriented due to the unevenness of the bamboo surface, leading to the cross-linked $\mathrm{ZnO}$ nanowalls observed most frequently. Moreover, the $\mathrm{ZnO}$ nanosheets were interconnected with each other and had an uneven surface morphology on a large scale with diameters of about $0.5 \sim 1 \mu \mathrm{m}$. In the corresponding EDS spectrum of the inset in Figure 2(c), Zn element with a strong peak could be detected, indicating that $\mathrm{ZnO}$ had been grown on the bamboo surface.

Figure 2(e) displayed the XRD patterns of OB, ZSB, and $\mathrm{CZNB}$. The diffraction peaks at about $16^{\circ}$ and $22^{\circ}$ were assigned to $\mathrm{OB}$ [29]. But, for ZSB, no other new diffraction peaks were detected from the XRD patterns except for the cellulose diffraction peaks from bamboo, which might be due to the fact that the crystal phase of $\mathrm{ZnO}$ sol consisted of amorphous $\mathrm{ZnO}$. After hydrothermal reaction, some new strong diffraction peaks were observed and all diffraction peaks could be assigned to the wurtzite-type ZnO (JCPDS, 36-1451). No excess peaks were detected, implying that only high purity $\mathrm{ZnO}$ nanostructure was formed following the hydrothermal reaction. Figure 2(f) presented the FTIR absorption spectra of $\mathrm{OB}$ and $\mathrm{CZNB}$. The absorption peaks at $3321 \mathrm{~cm}^{-1}$ became increasingly stronger, which was attributed to the stretching vibrations of hydroxyl groups indicating that more hydroxyl groups were assembled on the bamboo surface. The selfassembly of the cross-linked $\mathrm{ZnO}$ nanowalls was achieved by the hydrothermal reaction due to the interaction between the $\mathrm{O}-\mathrm{H}$ groups of bamboo surface and the deposited $\mathrm{ZnO}$ $[23,27]$. The absorption peaks at $2881 \mathrm{~cm}^{-1}$ were assigned to the $\mathrm{C}-\mathrm{H}$ stretching vibrations [30]. As we all know, the peaks around $500 \mathrm{~cm}^{-1}$ were due to the vibration of metaloxygen $(\mathrm{M}-\mathrm{O})$ bonds as reported in the literature [31]. The wide band observed in the $400-600 \mathrm{~cm}^{-1}$ frequency range was characteristic of $\mathrm{ZnO}$ as previously reported [32].

Based on the results mentioned above, a schematic diagram of the formation of CZNB using a hydrothermal method was proposed, which could be helpful in understanding the growth mechanism of wurtzite $\mathrm{ZnO}$ on the bamboo surface. The porous bamboo substrate with abundant hydroxyl groups provided a chance for the deposition of $\mathrm{ZnO}$ nanomaterials on the bamboo surface under hydrothermal conditions (Figure 3(a)). When the bamboo substrate was immersed in $\mathrm{ZnO}$ sol solution, the zinc alkoxides from $\mathrm{ZnO}$ sol solution could adsorb onto the micronanoporous structure through strong hydrogen bond and electronic interactions (Figure 3(b)). With hydrothermal reaction, the zinc alkoxides continuously hydrolyzed to form $\mathrm{ZnO}$ seeds for the growth of CZNB (Figure 3(c)). Thus, the $\mathrm{ZnO}$ nanomaterials were covered and immobilized well in the bamboo surface.

$\mathrm{Rh} \mathrm{B}$ was adopted as a representative organic pollutant to evaluate the photocatalytic performance of CZNB as photocatalysts. In this experiment, the commercially available $\mathrm{TiO}_{2}$ P25 (Degussa, Germany) was used as a photocatalytic reference to help understand the photocatalytic activity of CZNB. The photocatalytic activities of the as-prepared samples and P25 were shown in Figure 4(a). The CZNB as photocatalysts showed the highest photocatalytic activity. The OB had a little photocatalytic activity of about $5.6 \%$ on $\mathrm{Rh}$ $\mathrm{B}$ during the whole process, which was mainly due to the 


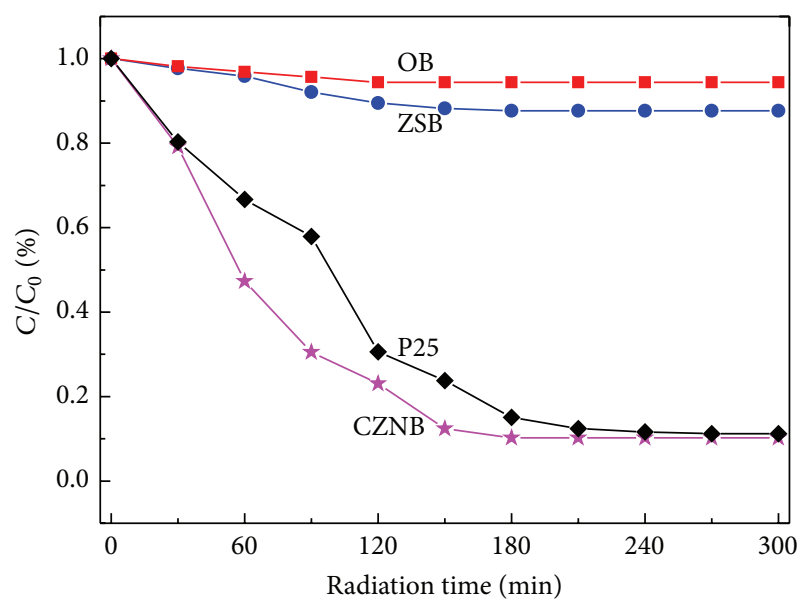

(a)

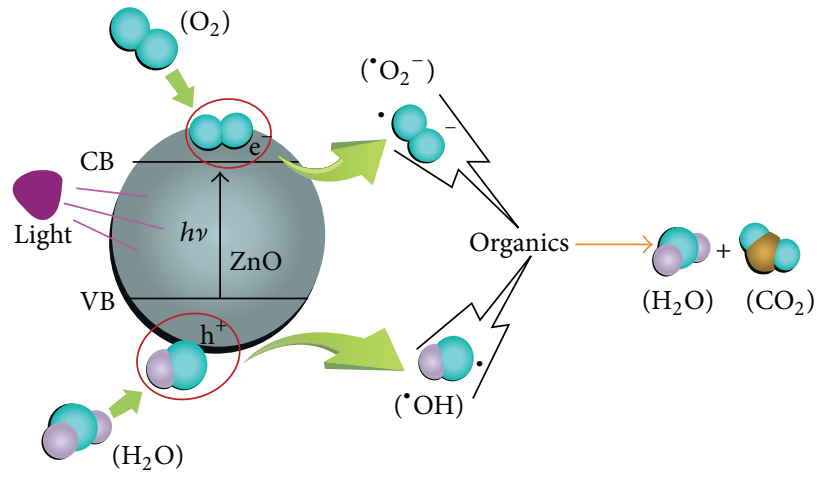

(b)

FIGURe 4: (a) Photocatalytic activity of OB, ZSB, P25, and CZNB, respectively. (b) Schematic photocatalytic mechanism of ZnO.

physical absorption effect of bamboo. In Figure 4(a), the Rh B degradation efficiency was about $12.3 \%$ for ZSB. However, the required time for an entire decolorization of $\mathrm{Rh} B$ over $\mathrm{CZNB}$ as photocatalysts was about $180 \mathrm{~min}$, which was much shorter than P25. The photocatalytic efficiency of CZNB was greatly enhanced, which was probably because the photocatalytic activity of $\mathrm{ZnO}$ particles strongly depends on some specific exposed crystal faces $[33,34]$. This result would contribute to the potential application of our $\mathrm{ZnO} /$ bamboo composite materials to the treatment of dye wastewater.

Based on the above results, the photocatalytic activities of CZNB under UV irradiation could be illuminated by Figure 4(b). When the bamboo-based photocatalysts were irradiated by UV light at $254 \mathrm{~nm}$, which was with photon energy higher than or equal to the band gap of $\mathrm{ZnO}$ nanocrystals, holes could react with water adhering to the surfaces of $\mathrm{ZnO}$ nanowalls to form highly reactive hydroxyl radicals $(\bullet \mathrm{OH})$. Meanwhile, on the surfaces of $\mathrm{ZnO}$ nanowalls, oxygen was reduced as an electron captor to superoxide radical anions $\left(\cdot \mathrm{O}_{2}{ }^{-}\right)$. The radical anions were further combined with $\mathrm{H}^{+}$to form $\bullet \mathrm{OOH}$ and $\bullet \mathrm{OOH}$ radicals and the trapped electrons combined to produce $\mathrm{H}_{2} \mathrm{O}_{2}$ and this led to production of hydroxyl radicals $(\bullet \mathrm{OH})$. The formed radicals had a powerful oxidation ability to degrade $\mathrm{Rh} B$ dye $[35,36]$.

Regeneration of $\mathrm{ZnO}$ photocatalyst was one of the key steps to make heterogeneous photocatalysis technology for practical applications. It was important to investigate the stability and repeatability of the as-synthesized CZNB as a photocatalyst in photocatalytic degradation of aqueous $\mathrm{Rh} \mathrm{B}$. So, in our work, CZNB was recycled for three times in the same photocatalytic reactions under ultraviolet irradiation. After each cycle, which lasted for $180 \mathrm{~min}$, the photocatalyst was separated from the suspension by tweezers, washed with deionized water, dried, and used for a new cycle. Figure 5 presented the degradation evolution of Rh B for CZNB as a photocatalyst at $180 \mathrm{~min}$ illumination for the first three cycles. Obviously, the photocatalytic activity of CZNB exhibited a

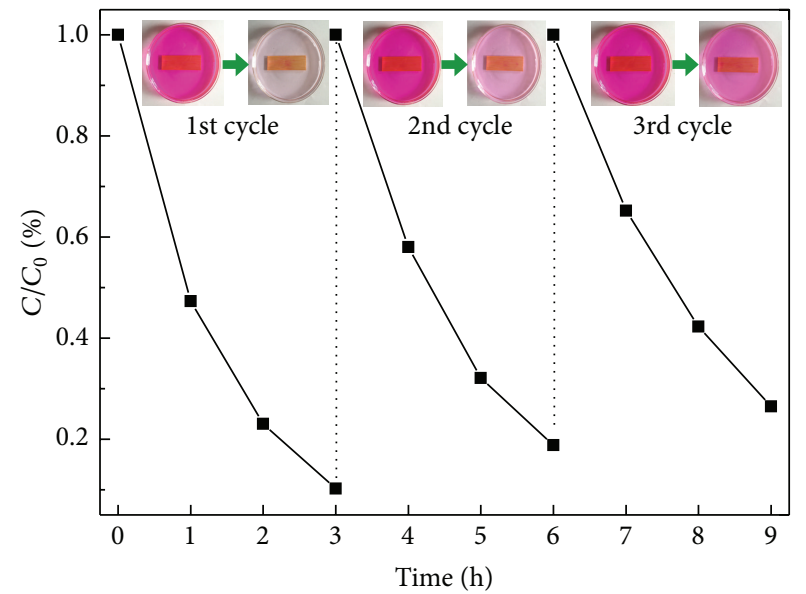

FIGURE 5: Photocatalytic activity of CZNB as a photocatalyst at 180 min illumination for the first three cycles. The insets were its corresponding macrographs, respectively.

little decline after three cycles, and the degradation ratio was still higher than $77 \%$. It was obvious that the Rh B solutions were degraded by CZNB under ultraviolet irradiation, resulting in the faded solution (Figure 5, insets).

\section{Conclusions}

The cross-linked $\mathrm{ZnO}$ nanowalls had been successfully immobilized onto the bamboo surface using the hydrothermal method. The wurtzite cross-linked $\mathrm{ZnO}$ nanowalls were attached to the bamboo surface through the hydroxyl group interactions. The cross-linked $\mathrm{ZnO}$ nanowalls on the bamboo surface showed a superior photocatalytic ability and could be used as recyclable photocatalysts. This study also provided a recycled green photocatalyst of the $\mathrm{ZnO} /$ bamboo composite materials. 


\section{Conflict of Interests}

The authors declare that there is no conflict of interests regarding the publication of this paper.

\section{Acknowledgment}

The work was financially supported by the Pre-Research Project of Research Center of Biomass Resource Utilization, Zhejiang A \& F University (2013SWZ01-03).

\section{References}

[1] Y. Zheng, L. Zheng, Y. Zhan, X. Lin, Q. Zheng, and K. Wei, "Ag/ZnO heterostructure nanocrystals: synthesis, characterization, and photocatalysis," Inorganic Chemistry, vol. 46, no. 17, pp. 6980-6986, 2007.

[2] Y. Zheng, Y. Cheng, Y. Wang et al., "Quasicubic $\alpha-\mathrm{Fe}_{2} \mathrm{O}_{3}$ nanoparticles with excellent catalytic performance," Journal of Physical Chemistry B, vol. 110, no. 7, pp. 3093-3097, 2006.

[3] C. T. Williams and D. A. Beattie, "Probing buried interfaces with non-linear optical spectroscopy," Surface Science, vol. 500, no. 1-3, pp. 545-576, 2002.

[4] R. Gong, Y. Ding, M. Li, C. Yang, H. Liu, and Y. Sun, "Utilization of powdered peanut hull as biosorbent for removal of anionic dyes from aqueous solution," Dyes and Pigments, vol. 64, no. 3, pp. 187-192, 2005.

[5] I. Kanu and O. Achi, "Industrial effluents and their impact on water quality of receiving rivers in Nigeria," Journal of Applied Technology in Environmental Sanitation, vol. 1, no. 1, pp. 75-86, 2011.

[6] J. Yu, M. Jaroniec, H. Yu, and W. Fan, "Synthesis, characterization, properties, and applications of nanosized photocatalytic materials," Journal of Nanomaterials, vol. 2012, Article ID 783686, 17 pages, 2012.

[7] W. Asghar, I. A. Qazi, H. Ilyas, A. A. Khan, M. A. Awan, and M. Rizwan Aslam, "Comparative solid phase photocatalytic degradation of polythene films with doped and undoped $\mathrm{TiO}_{2}$ nanoparticles," Journal of Nanomaterials, vol. 2011, Article ID 461930, 12 pages, 2011.

[8] M. H. Habibi and M. K. Sardashti, "Preparation of glass platesupported nanostructure $\mathrm{ZnO}$ thin film deposited by sol-gel spin-coating technique and its photocatalytic degradation to monoazo textile dye," Journal of Nanomaterials, vol. 2008, Article ID 356765, 5 pages, 2008.

[9] S.-M. Lee, G. Grass, G.-M. Kim et al., "Low-temperature $\mathrm{ZnO}$ atomic layer deposition on biotemplates: flexible photocatalytic ZnO structures from eggshell membranes," Physical Chemistry Chemical Physics, vol. 11, no. 19, pp. 3608-3614, 2009.

[10] L. Wang, L. Shen, L. Zhu, H. Jin, and N. Bing, "Preparation and photocatalytic properties of $\mathrm{SnO}_{2}$ coated on nitrogen-doped carbon nanotubes," Journal of Nanomaterials, vol. 2012, Article ID 794625, 6 pages, 2012.

[11] I. Poulios and I. Aetopoulou, "Photocatalytic degradation of the textile dye reactive orange 16 in the presence of $\mathrm{TiO}_{2}$ suspensions," Environmental Technology, vol. 20, no. 5, pp. 479487, 1999.

[12] K. Onda, B. Li, J. Zhao, and H. Petek, "The electronic structure of methanol covered $\mathrm{TiO}_{2}(110)$ surfaces," Surface Science, vol. 593, no. 1-3, pp. 32-37, 2005.
[13] Y. Zheng, C. Chen, Y. Zhan et al., "Photocatalytic activity of $\mathrm{Ag} / \mathrm{ZnO}$ heterostructure nanocatalyst: correlation between structure and property," Journal of Physical Chemistry C, vol. 112, no. 29, pp. 10773-10777, 2008.

[14] C. F. Guo, S. Cao, J. Zhang et al., "Topotactic transformations of superstructures: from thin films to two-dimensional networks to nested two-dimensional networks," Journal of the American Chemical Society, vol. 133, no. 21, pp. 8211-8215, 2011.

[15] C. F. Guo, J. Zhang, M. Wang, Y. Tian, and Q. Liu, "A strategy to prepare wafer scale bismuth compound superstructures," Small, vol. 9, no. 14, pp. 2394-2398, 2013.

[16] C. Guo, T. Sun, Q. Liu, Z. Suo, and Z. Ren, "Highly stretchable and transparent nanomesh electrodes made by grain boundary lithography," Nature Communications, vol. 5, article 3121, 2014.

[17] A. Phuruangrat, O. Yayapao, T. Thongtem, and S. Thongtem, "Synthesis and characterization of europium-doped zinc oxide photocatalyst," Journal of Nanomaterials, vol. 2014, Article ID 367529, 9 pages, 2014.

[18] S. L. Wang, H. W. Zhu, W. H. Tang, and P. G. Li, "Propellershaped $\mathrm{ZnO}$ nanostructures obtained by chemical vapor deposition: photoluminescence and photocatalytic properties," Journal of Nanomaterials, vol. 2012, Article ID 594290, 5 pages, 2012.

[19] E. S. Jang, J. H. Won, S. J. Hwang, and J. H. Choy, "Fine tuning of the face orientation of $\mathrm{ZnO}$ crystals to optimize their photocatalytic activity," Advanced Materials, vol. 18, no. 24, pp. 3309-3312, 2006.

[20] J. Zeng, S. Liu, J. Cai, and L. Zhang, “TiO2 immobilized in cellulose matrix for photocatalytic degradation of phenol under weak UV light irradiation," Journal of Physical Chemistry C, vol. 114, no. 17, pp. 7806-7811, 2010.

[21] S. H. Imam, S. H. Gordon, L. Mao, and L. Chen, "Environmentally friendly wood adhesive from a renewable plant polymer: characteristics and optimization," Polymer Degradation and Stability, vol. 73, no. 3, pp. 529-533, 2001.

[22] M. Singh, J. Martínez-Fernández, and A. R. de ArellanoLópez, "Environmentally conscious ceramics (ecoceramics) from natural wood precursors," Current Opinion in Solid State and Materials Science, vol. 7, no. 3, pp. 247-254, 2003.

[23] Q. Sun, H. Yu, Y. Liu, J. Li, Y. Lu, and J. F. Hunt, "Improvement of water resistance and dimensional stability of wood through titanium dioxide coating," Holzforschung, vol. 64, no. 6, pp. 757761, 2010

[24] Y. Lu, S. Xiao, R. Gao, J. Li, and Q. Sun, "Improved weathering performance and wettability of wood protected by $\mathrm{CeO}_{2}$ coating deposited onto the surface," Holzforschung, vol. 68, no. 3, pp. 345-351, 2013.

[25] Q. Sun, Y. Lu, and Y. Liu, "Growth of hydrophobic $\mathrm{TiO}_{2}$ on wood surface using a hydrothermal method," Journal of Materials Science, vol. 46, no. 24, pp. 7706-7712, 2011.

[26] Q. Sun, Y. Lu, D. Yang, J. Li, and Y. Liu, "Preliminary observations of hydrothermal growth of nanomaterials on wood surfaces," Wood Science and Technology, vol. 48, no. 1, pp. 5158, 2014.

[27] Q. Sun, Y. Lu, H. Zhang et al., "Improved UV resistance in wood through the hydrothermal growth of highly ordered $\mathrm{ZnO}$ nanorod arrays," Journal of Materials Science, vol. 47, no. 10, pp. 4457-4462, 2012.

[28] Q. Sun, Y. Lu, H. Zhang et al., "Hydrothermal fabrication of rutile $\mathrm{TiO}_{2}$ submicrospheres on wood surface: an efficient method to prepare UV-protective wood," Materials Chemistry and Physics, vol. 133, no. 1, pp. 253-258, 2012. 
[29] Y. Yu, Z. Jiang, G. Wang, G. Tian, H. Wang, and Y. Song, "Surface functionalization of bamboo with nanostructured ZnO," Wood Science and Technology, vol. 46, no. 4, pp. 781-790, 2012.

[30] K. K. Pandey, "A study of chemical structure of soft and hardwood and wood polymers by FTIR spectroscopy," Journal of Applied Polymer Science, vol. 71, no. 12, pp. 1969-1975, 1999.

[31] S. K. Dhoke, T. J. M. Sinha, P. Dutta, and A. S. Khanna, "Formulation and performance study of low molecular weight, alkyd-based waterborne anticorrosive coating on mild steel," Progress in Organic Coatings, vol. 62, no. 2, pp. 183-192, 2008.

[32] G. Xiong, U. Pal, J. G. Serrano, K. B. Ucer, and R. T. Williams, "Photoluminescence and FTIR study of $\mathrm{ZnO}$ nanoparticles: the impurity and defect perspective," Physica Status Solidi C, vol. 3, no. 10, pp. 3577-3581, 2006.

[33] Y. Yamaguchi, M. Yamazaki, S. Yoshihara, and T. Shirakashi, "Photocatalytic $\mathrm{ZnO}$ films prepared by anodizing," Journal of Electroanalytical Chemistry, vol. 442, no. 1-2, pp. 1-3, 1998.

[34] L. Jing, Z. Xu, X. Sun, J. Shang, and W. Cai, "The surface properties and photocatalytic activities of $\mathrm{ZnO}$ ultrafine particles," Applied Surface Science, vol. 180, no. 3-4, pp. 308-314, 2001.

[35] S. Chakrabarti and B. K. Dutta, "Photocatalytic degradation of model textile dyes in wastewater using $\mathrm{ZnO}$ as semiconductor catalyst," Journal of Hazardous Materials, vol. 112, no. 3, pp. 269278, 2004.

[36] J. Yu and X. Yu, "Hydrothermal synthesis and photocatalytic activity of zinc oxide hollow spheres," Environmental Science and Technology, vol. 42, no. 13, pp. 4902-4907, 2008. 

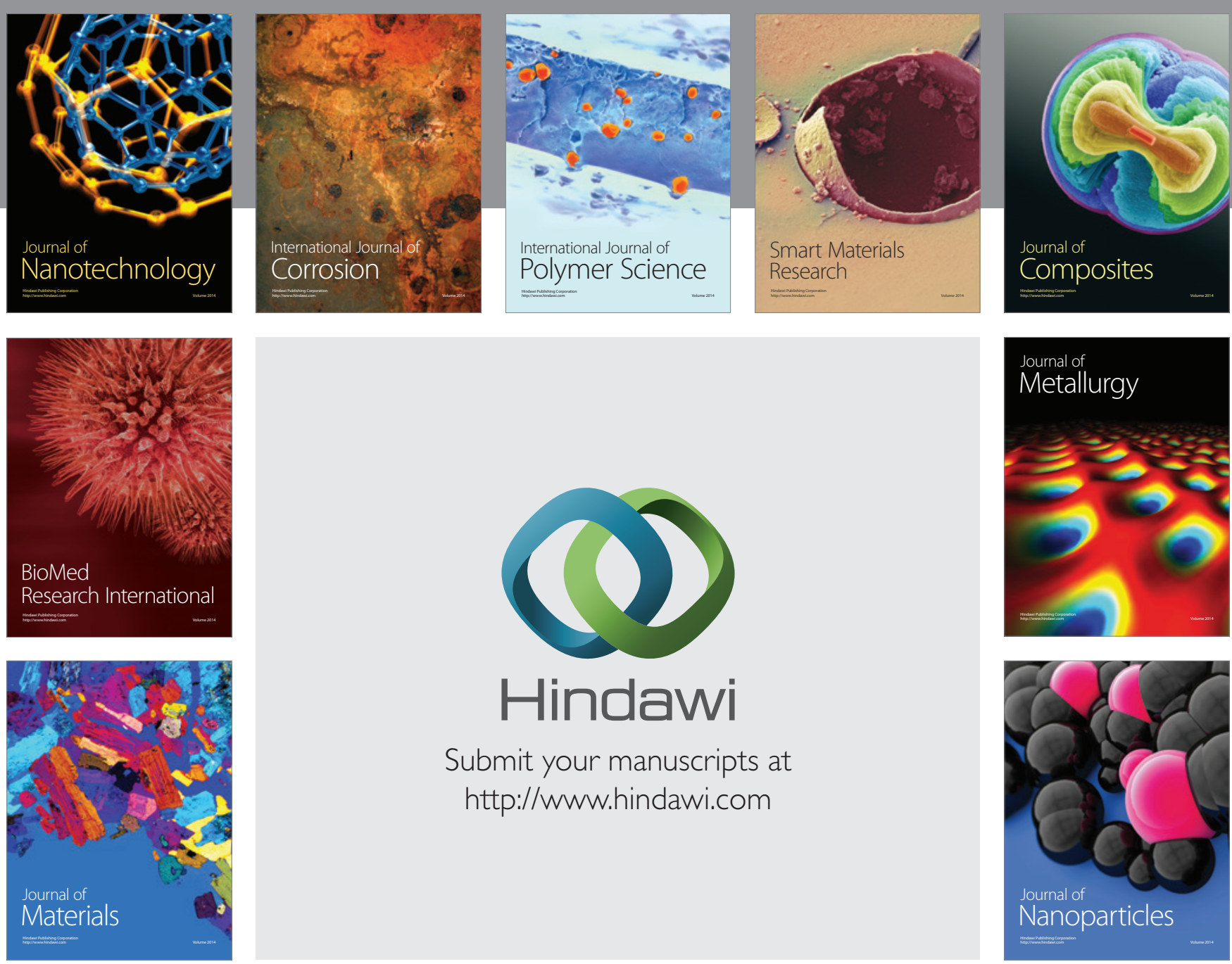

Submit your manuscripts at http://www.hindawi.com
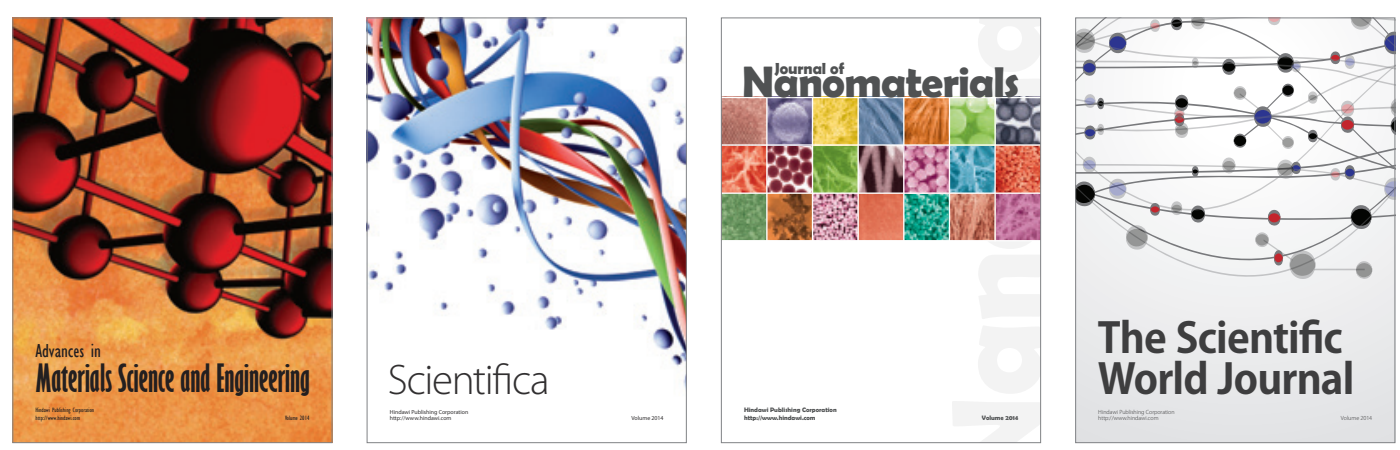

\section{The Scientific World Journal}
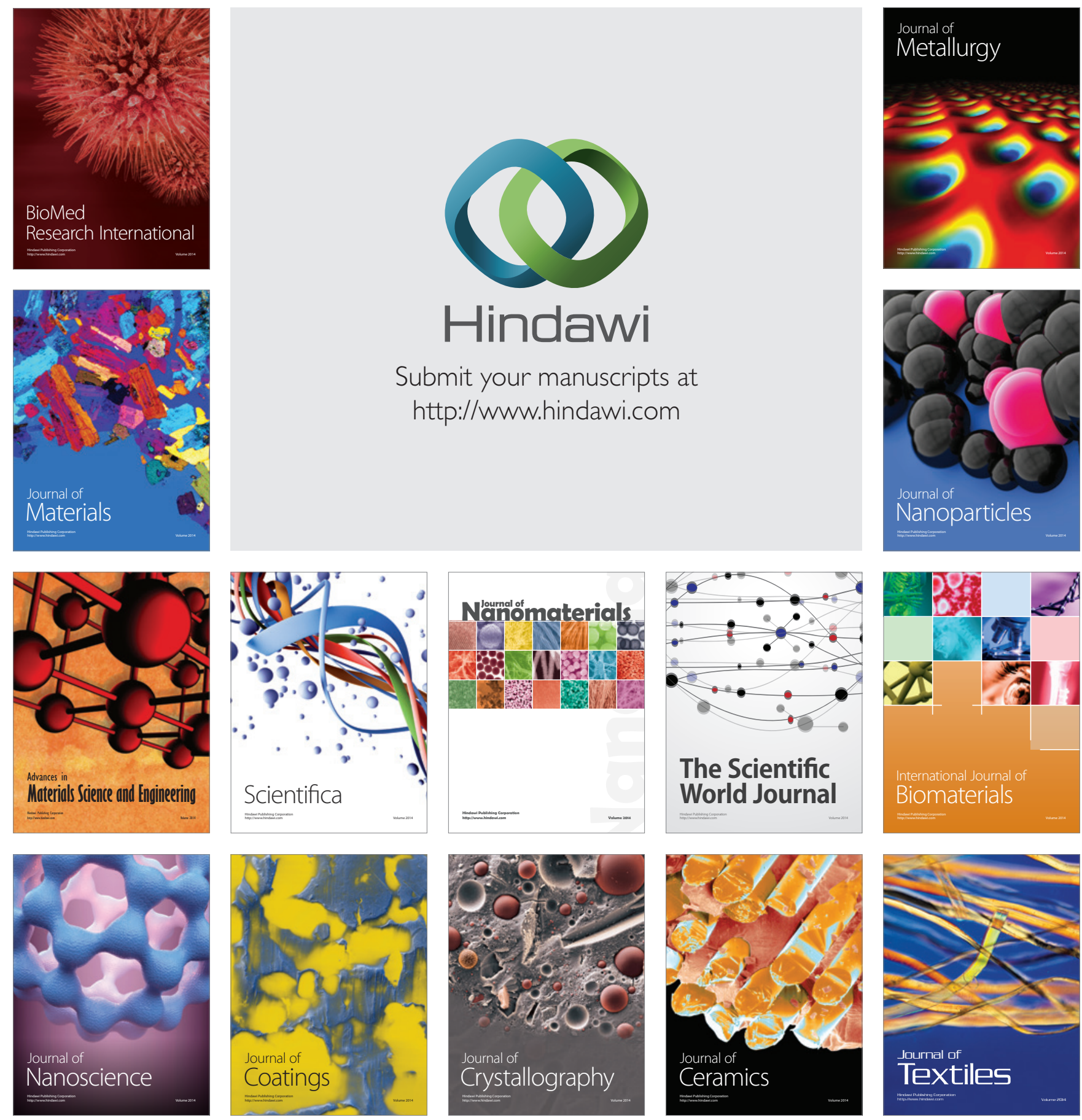